\title{
A mere exposure effect for transformed three-dimensional objects: Effects of reflection, size, or color changes on affect and recognition
}

\author{
JOHN G. SEAMON, DONNA GANOR-STERN, MICHAEL J. CROWLEY, SARAH M. WILSON, \\ WENDY J. WEBER, CORINNE M. O'ROURKE, and JOSEPH K. MAHONEY \\ Wesleyan University, Middletown, Connecticut
}

\begin{abstract}
If the mere exposure effect is based on implicit memory, recognition and affect judgments should be dissociated by experimental variables in the same manner as other explicit and implicit measures. Consistent with results from recognition and picture naming or object decision priming tasks (e.g., Biederman \& E. E. Cooper, 1991, 1992; L. A. Cooper, Schacter, Ballesteros, \& Moore, 1992), the present research showed that recognition memory but not affective preference was impaired by reflection or size transformations of three-dimensional objects between study and test. Stimulus color transformations had no effect on either measure. These results indicate that representations that support recognition memory code spatial information about an object's left-right orientation and size, whereas representations that underlie affective preference do not. Insensitivity to surface feature changes that do not alter object form appears to be a general characteristic of implicit memory measures, including the affective preference task.
\end{abstract}

Explicit memory refers to conscious, intentional recollection of past experience, whereas implicit memory refers to unintentional, nonconscious retrieval of previously presented information. Over the past decade, research has shown that explicit and implicit memory can be dissociated by a variety of experimental variables (see Graf, 1994; Moscovitch, Goshen-Gottstein, \& Vriezen, 1994; Richardson-Klavehn \& Bjork, 1988; Roediger \& McDermott, 1993; Schacter, 1987, for reviews). One of those variables involves physical stimulus transformations. When stimuli are transformed between study and test by changes in presentation modality (e.g., auditory to visual presentation) or format (e.g., pictures to words), those changes impair implicit, not explicit memory (see, e.g., Roediger \& Blaxton, 1987; Schacter \& Church, 1992; Weldon, 1991). These results imply representational specificity for implicit measures. However, a notable exception occurs for object stimuli transformed by surface changes in left-right orientation or size. These changes impair explicit, not implicit, performance (see, e.g., Biederman \& E. E. Cooper, 1992; L. A. Cooper, Schacter, Ballesteros, \& Moore, 1992). If implicit memory for objects is characteristically insensitive to transformations of reflectance or size, this finding should be demonstrated by all implicit memory measures, including affective preference due to mere exposure.

We thank Michael Masson and the two reviewers, along with Marisa Carrasco and Richard Marsh, for helpful comments on an earlier draft of this paper. Correspondence should be addressed to J. G. Seamon, Department of Psychology, Wesleyan University, Middletown, CT 06459-0408 (e-mail: jseamon@wesleyan.edu).
The mere exposure effect was first described by $\mathrm{Za}$ jonc (1968) as the increase in positive affect that results from the repeated presentation of previously unfamiliar stimuli. It is demonstrated even for stimuli that are not recognized. For example, Kunst-Wilson and Zajonc (1980) found that when participants were presented with 10 irregular polygons five times each at a 1-msec exposure duration, the participants were unable to discriminate those stimuli from comparable distracters in a forcedchoice recognition memory test. However, they selected the target stimuli greater than chance in a forced-choice affective preference test. This study and others (e.g., Bornstein, Leone, \& Galley, 1987; Mandler, Nakamura, \& Van Zandt, 1987; Seamon, Brody, \& Kauff, 1983a, 1983b; Seamon, Marsh, \& Brody, 1984) demonstrated that participants can "like" previously shown stimuli without recognizing them, a finding that led theorists to describe the mere exposure effect as an expression of implicit memory (Schacter, 1987; Squire, 1992).

If the mere exposure effect demonstrates implicit memory, it should be influenced by experimental variables in the same manner as other implicit measures. Seamon et al. (1995) tested this assumption using variables selected from the implicit memory research of Schacter, L. A. Cooper, and their colleagues (Schacter, Cooper, \& Delaney, 1990; Schacter, Cooper, Delaney, Peterson, \& Tharan, 1991). Schacter et al. (1990, 1991) presented participants with possible objects that could exist as threedimensional forms and impossible objects that contained surface or edge violations that prevented them from existing as three-dimensional structures. Following encoding, the participants were given a recognition memory test 
("Was this object presented during study?") or an object decision test ("Is this object possible or impossible?") on studied and nonstudied objects. Object decision priming would be demonstrated by greater object classification accuracy for studied than nonstudied objects. Schacter et al. observed the following dissociations: Object decision priming was dependent on global structural encoding (encoding each stimulus as a three-dimensional object rather than encoding a specific feature of each object), and recognition was not (1990); recognition was influenced by the number of stimulus exposures at study, and priming was not (1991); and recognition was observed for possible and impossible objects, whereas priming was found only for possible objects $(1990,1991)$.

Seamon et al. (1995) manipulated these variables, using Schacter et al.'s $(1990,1991)$ possible and impossible objects, in the mere exposure paradigm. After encoding the stimuli, the participants were given tests of forcedchoice recognition ("Which stimulus did you see before?") and affective preference ("Which stimulus do you like?"). Seamon et al. found that recognition was influenced by the number of stimulus exposures at study, and affective preference was not. However, affective preference was not dependent on global structural encoding, and it was observed for previously viewed possible and impossible objects. The authors suggested that affect judgments may be based on global structural descriptions of possible objects or possible parts of impossible objects. Seamon et al. concluded that the mere exposure paradigm satisfied both conditions of Schacter, Bowers, and Booker's (1989) retrieval intentionality criterion for distinguishing between explicit and implicit measures. Specifically, only the recognition test asked participants for intentional recollection, and specific experimental variables dissociated performance on both tests (see Seamon et al., 1983a, 1983b, 1984, for additional dissociations).

The present study extended that research by examining the effects of stimulus transformations involving left-right orientation, size, or color on measures of recognition and affect. If both measures are based on explicit memory, surface transformations between study and test might be expected to impair performance on both. But if the affective preference test is a measure of implicit memory, the affect results should mimic those found in other transformation experiments using different implicit measures: Affective preference judgments should not be influenced by surface transformations that preserve object form. This result would suggest that insensitivity to these transformations is a general characteristic of implicit memory. This finding would also indicate that the representational system that supports affect judgments does not code information about an object's left-right orientation, size, or color. This conclusion, based on the logic of L. A. Cooper et al. (1992), holds that if a stimulus change between study and test impairs explicit or implicit memory, we may infer that the representational system used by each task codes the type of information that was changed. On the other hand, if explicit or implicit performance is unimpaired by a stimu- lus change, the representational system for each task is insensitive to that information. Each transformation was examined separately in the experiments that follow.

\section{EXPERIMENT 1 Reflection}

Repetition priming in the picture naming task is demonstrated by faster and more accurate object naming the second time an object is shown. Biederman and E. E. Cooper (1991) found that object reflection from the first to the second presentation had no effect on priming. Similarly, L. A. Cooper et al. (1992) found that while object reflection between study and test impaired recognition memory, it had no effect on object decision priming. If the mere exposure effect is based on implicit memory, the same dissociation should be observed: Recognition should be impaired by a stimulus reflection transformation, and affective preference should not.

\section{Method}

Subjects, Design, and Materials. The subjects, 48 Wesleyan University students who received introductory psychology credit, took part in a $2 \times 2 \times 2 \times 2$ mixed factorial design. Study-test orientation (same vs. reflected) and test order (recognition-affect vs. affect-recognition) were manipulated as between-subjects variables; object type (possible vs. impossible objects) and test type (recognition vs. affective preference) were manipulated as withinsubjects variables. The orientation and test order variables yielded four experimental groups, each composed of 12 subjects.

The stimuli were obtained from examples of possible and impossible objects provided by Schacter and L. A. Cooper (e.g., L. A. Cooper et al., 1992; Schacter et al., 1990, 1991). They were photographed as negative slides and projected on a screen by a Gerbrands projection tachistoscope. All subtended a visual angle of approximately $5^{\circ}$ when viewed from a distance of $2.7 \mathrm{~m}$, and they appeared as green objects on a dark surround when shown through a green photographic filter attached to the lens shutter of the tachistoscope. The experiment was conducted under conditions of low room illumination.

Procedure. The study and test procedures were similar to those used by Seamon et al. (1995, Experiments 2 and 3), and the stimuli were identical to the "block" figures used in that research. Subjects were told that they would take part in a perceptual decisionmaking experiment wherein they would have to decide if line drawings of three-dimensional figures represented possible or impossible objects. Following exposure to examples of each object type, the subjects were shown a series of 12 objects $(6$ possible and 6 impossible) five times in five random orders of 12 . Each object was presented in the center of the visual field for $2.5 \mathrm{sec}$, followed by a $3.5 \mathrm{sec}$ interstimulus interval. The subjects, who were tested in groups of up to 6 , were instructed to look at each figure for the full exposure duration, and then circle possible or impossible on their answer sheets. They were not informed of the subsequent recognition and affective preference tests.

After viewing the study stimuli, the subjects were presented with 12 test trials. Each test trial, shown for $1 \mathrm{sec}$ followed by a $3.5-\mathrm{sec}$ intertrial interval, consisted of a target object from the study set and a $90^{\circ}$ rotated version of that same object as a distracter presented side by side on the screen. Half of the distracters were formed by rotating the targets $90^{\circ}$ clockwise in the picture plane, and half were made by rotating the targets $90^{\circ}$ counterclockwise. This procedure for constructing distracters by rotating targets ensured that the target and distracter pairs were matched for size and complexity. Targets appeared on the left for half of the test trials, and 
Table I

\begin{tabular}{|c|c|c|c|c|c|c|c|c|c|c|c|c|}
\hline \multirow{4}{*}{$\begin{array}{l}\text { Study-Test } \\
\text { Orientation } \\
\end{array}$} & \multicolumn{6}{|c|}{ Recognition Test } & \multicolumn{6}{|c|}{ Affect Test } \\
\hline & \multicolumn{4}{|c|}{ Object Type } & \multirow[b]{3}{*}{$M$} & \multirow[b]{3}{*}{$S E$} & \multicolumn{4}{|c|}{ Object Type } & \multirow[b]{3}{*}{$M$} & \multirow[b]{3}{*}{$S E$} \\
\hline & \multicolumn{2}{|c|}{ Possible } & \multicolumn{2}{|c|}{ Impossible } & & & \multicolumn{2}{|c|}{ Possible } & \multicolumn{2}{|c|}{ Impossibie } & & \\
\hline & $M$ & $S E$ & $M$ & $S E$ & & & $M$ & $S E$ & $M$ & $S E$ & & \\
\hline Same & 88.2 & 3.2 & 68.7 & 5.9 & 78.5 & 3.6 & 67.4 & 5.6 & 54.2 & 5.1 & 60.8 & 3.9 \\
\hline Reflected & 62.6 & 4.5 & 54.2 & 4.4 & 58.4 & 3.2 & 70.1 & 4.3 & 61.1 & 4.2 & 65.6 & \\
\hline$M$ & 75.4 & 3.3 & 61.5 & 3.8 & & & 68.7 & 3.5 & 57.6 & 3.3 & & \\
\hline
\end{tabular}

Note-Chance performance is $50 \%$ for both tests.

on the right for the other half. Their location was randomized and counterbalanced over trials.

The subjects examined each test pair and, depending on instructions, selected the object they saw before (forced-choice recognition judgment) or selected the object they liked best (forced-choice affect judgment) by circling a left or right choice on their answer sheets. Subjects taking the recognition memory test were informed that the target objects might appear in the same orientation as study or in a reflected orientation. They were told to try to recognize the target object regardless of its left-right orientation. After completing the first test, the subjects were informed of the second test and the alternate judgment rule. They were given 12 additional test trials in a new random order. Half of the subjects received recognition before affect, and half received the reverse order. Finally, the standard and reflected stimuli were counterbalanced to ensure that any performance differences would not be due to stimulus differences in the same or reflected orientation conditions.

\section{Results and Discussion}

Following Seamon et al. (1995), separate analyses of variance (ANOVAs) were conducted on the recognition, affective preference, and combined recognition and affect data for each of the experiments reported. Unless otherwise specified, all results are based on the analyses of the single tests.

The results showed an effect of test order for recognition $\left[F(1,44)=7.12, M S_{\mathrm{e}}=.059, p<.02\right]$, but not affect $(F<1)$. In this instance, recognition was better when tested first than second, a finding that has not been regularly observed (e.g., Seamon et al., 1983a, 1983b, 1984, 1995). Moreover, test order did not interact with other variables, and separate analyses of recognition and affect for the first test only (test type as a between-subjects variable) yielded the same statistical results as those obtained from repeated testing (test type as a within-subjects variable). Consequently, the data were pooled over test order and are presented in Table 1.

Table 1 shows the effects of the two primary variablesstimulus orientation and object type-on both measures. First, reflecting the stimuli between study and test impaired recognition $\left[F(1,44)=16.32, M S_{\mathrm{e}}=.059, p<.0002\right]$, but not affect $(F<1$; the power of the affective preference test was .99 based on an estimate of the maximum effect size obtained from the recognition memory test). Second, performance was better for possible than for impossible objects for recognition $\left[F(1,44)=14.71, M S_{\mathrm{e}}=\right.$ $.032, p<.0004]$ and affect $\left[F(1,44)=6.82, M S_{\mathrm{e}}=.043\right.$, $p<.02]$. Third, collapsing the data in Table 1 over the stimulus orientation conditions (bottom row of Table 1) indicated that recognition and affective preference were greater than chance for possible and impossible objects by the results of one-tailed $t$ tests (Bonferroni correction $=.05 / 2$ for each measure; $p s<.05$ ). Finally, no other effects or interactions were significant (all $p \mathrm{~s}>.05$ ).

This experiment showed that stimulus reflection dissociated recognition memory and affective preference in the same manner that L. A. Cooper et al. (1992) observed for recognition and object decision priming. Reflection impaired recognition, but it had no effect on affective preference. This result extends prior research on the effect of reflection on explicit and implicit memory (Biederman \& E. E. Cooper, 1991; L. A. Cooper et al., 1992 ) and provides additional support for the view that the affective preference test is a measure of implicit memory.

\section{EXPERIMENT 2 Size}

Stimuli can be changed between study and test by making them smaller or larger than originally studied. These size transformations have dissociated explicit and implicit memory in the same manner as transformations of left-right orientation: they impaired recognition without influencing priming. These results were observed in normal and amnesic populations in studies of recognition (Jolicoeur, 1987; Kolers, Duchnicky, \& Sundstroem, 1985; Milliken \& Jolicoeur, 1992), recognition and picture naming tasks (Biederman \& E. E. Cooper, 1992; Cave $\&$ Squire, 1992), and recognition and object decision tasks (L. A. Cooper et al., 1992; Schacter, L. A. Cooper, \& Treadwell, 1993). For recognition, the direction of the size change does not matter as much as the magnitude of the change. In general, the larger the size ratio between study and test, the greater the recognition impairment (Jolicoeur, 1987). Our hypothesis relating mere exposure to implicit memory predicts that recognition, not affective preference, should be impaired by an object size change.

\section{Method}

The design, materials, and procedure were similar to those of Experiment 1. The subjects, 64 additional Wesleyan University students who received introductory psychology credit, served in a $2 \times 2 \times 2 \times 2$ mixed factorial design. Study-test size (same vs. different) and test order (recognition-affect vs. affect-recognition) were manipulated as between-subjects variables: object type (possible vs. impossible objects) and test type (recognition vs. affec- 
Table 2

Mean Percentage of Target Objects Selected in Experiment 2: Size

\begin{tabular}{|c|c|c|c|c|c|c|c|c|c|c|c|c|}
\hline \multirow{4}{*}{$\begin{array}{c}\text { Study-Test } \\
\text { Stimulus Size }\end{array}$} & \multicolumn{6}{|c|}{ Recognition Test } & \multicolumn{6}{|c|}{ Affect Test } \\
\hline & \multicolumn{4}{|c|}{ Object Type } & \multirow[b]{3}{*}{$M$} & \multirow[b]{3}{*}{$S E$} & \multicolumn{4}{|c|}{ Object Type } & \multirow[b]{3}{*}{$M$} & \multirow[b]{3}{*}{$S E$} \\
\hline & \multicolumn{2}{|c|}{ Possible } & \multicolumn{2}{|c|}{ Impossible } & & & \multicolumn{2}{|c|}{ Possible } & \multicolumn{2}{|c|}{ Impossible } & & \\
\hline & $M$ & $S E$ & $M$ & $S E$ & & & $M$ & $S E$ & $M$ & $S E$ & & \\
\hline Same & 92.7 & 1.8 & 80.2 & 2.3 & 86.5 & 1.7 & 72.9 & 4.0 & 66.1 & 5.0 & 69.5 & 3.2 \\
\hline Different & 82.3 & 2.6 & 68.7 & 4.0 & 75.5 & 2.5 & 75.0 & 4.4 & 68.2 & 3.8 & 71.6 & 2.9 \\
\hline$M$ & 87.5 & 1.7 & 74.5 & 2.4 & & & 74.0 & 3.0 & 67.2 & 3.1 & & \\
\hline
\end{tabular}

tive preference) were manipulated as within-subjects variables. For the study-test size-different conditions, half of the subjects were tested on figures that were smaller than those originally studied, and half were tested on larger figures.

The study and test figures were the same as those used in Experiment 1 . For the size-constant conditions at study and test, each figure subtended a visual angle of approximately $5^{\circ}$ when viewed from a distance of $2.7 \mathrm{~m}$. For the size-transformed conditions, the size of the study figures was the same as that for the size-constant conditions. However, the test figures in the size-transformed conditions were adjusted to be either all smaller or all larger by changing the size of the objects on the slides and the viewing distance of the subjects. For the size-smaller transformed condition, each figure subtended an approximate visual angle of $2^{\circ}$ when viewed from a distance of $4.1 \mathrm{~m}$; for the size-larger condition, each figure subtended a visual angle of approximately $12.5^{\circ}$ when viewed from a distance of $1.6 \mathrm{~m}$. These conditions resulted in a size ratio of $1: 2.5$ for standard and transformed figures, matching the size ratio used by L. A. Cooper et al. (1992) and Schacter et al. (1993). These transformations produced stimulus differences in perceived and retinal size, a condition found in all size transformation experiments except that of Milliken and Jolicoeur (1992), who separated these factors and found that recognition was impaired only when perceived size was varied. Milliken and Jolicoeur also informed subjects that target objects on the recognition test might appear in a different size. Subjects in the present experiment were similarly informed that stimuli might be smaller or larger in size and that they should try to recognize the target object regardless of its test size. All other aspects of procedure were identical to those in Experiment 1

\section{Results and Discussion}

Because test order effects were absent for recognition and affect (both $F_{\mathrm{S}}<1$ ), the data were collapsed over test order and are presented in Table 2. As in the previous experiment, performance was better for possible than for impossible objects for recognition $\left[F(1,60)=35.41, M S_{\mathrm{e}}=\right.$ $.015, p<.0001]$ and affect $\left[F(1,60)=4.66, M S_{\mathrm{e}}=.031\right.$, $p<.05]$. And, when the data in Table 2 were pooled over stimulus size conditions (bottom row of Table 2), greater than chance recognition and affective preference were indicated by one-tailed $t$ tests for possible and impossible objects (Bonferroni correction $=.05 / 2$ for each measure; $p s<.05)$.

Table 2 also shows the effect of the size transformation on both measures. Test figures that were smaller or larger than study figures impaired recognition $[F(1,60)=$ $\left.10.76, M S_{\mathrm{e}}=.036, p<.002\right]$ without influencing affect $(F<1$; the power of this affective preference test was .96 based on an estimate of the maximum effect size obtained from the corresponding recognition test), and there were no size change direction effects (smaller vs. larger sizes) on either measure (both $p s>.05$ ). These findings extend previous research by showing that a size transformation can dissociate recognition and affective preference in the same manner as has been observed for recognition and picture naming (Biederman \& E. E. Cooper, 1991) or object decision priming tasks (L. A. Cooper et al., 1992). For a size ratio of $1: 2.5$, implicit memory indexed by object decision priming or affective preference tasks is insensitive to size transformations. We note that when we conducted this experiment using a size ratio of $1: 1.5$ with 48 additional subjects under the same study and test conditions, a size transformation effect was not observed for recognition or affect (both $F \mathrm{~s}<1$; Seamon et al., 1994). Consistent with Jolicoeur (1987), recognition is sensitive to the magnitude of the size ratio.

\section{EXPERIMENT 3 Color}

Biederman and $\mathrm{Ju}$ (1988) reported that object color is largely unimportant for object identification. In their studies, participants named or verified black-and-white line drawings of objects as quickly and as accurately as colored photographs of those objects. Moreover, this result was obtained for objects whose color was diagnostic for identification (e.g., a banana) and objects whose color was not (e.g., a mitten). Yet, other research has shown that colored objects can be named or classified faster than comparable black-and-white objects (e.g., Ostergaard \& Davidoff, 1985; Price \& Humphreys, 1989; Wurm, Legge, Isenberg, \& Luebker, 1993). Price and Humphreys (1989) have suggested that the observance of an effect of color on object identification may depend on the strength of association between the color and object and the degree of difficulty of the identification task. Color may facilitate object identification when it is highly associated with an object and the identification task has been made difficult (e.g., employing objects that are similar in form or otherwise poorly distinguished by shape)

In terms of the present research, there are only a few memory studies that have varied stimulus focal or background color between study and test. However, these studies report a consistent finding: A stimulus color transformation has little effect on priming. For example, Cave, Bost, and Cobb (1996) found that an arbitrary (nondiagnostic) color change in repeated common objects (object 
drawings from Snodgrass \& Vanderwart, 1980) did not reduce the magnitude of repetition priming indexed by response times in a picture naming task. Nor did an arbitrary change in the print color of words between study and test impair word-stem completion performance (Jacoby, Toth, \& Yonelinas, 1993). Finally, affective preference for previously exposed random polygons was not affected by a change in the background color of the stimuli between study and test (Bonanno \& Stillings, 1986). But a change in arbitrary stimulus color may have a modest effect on recognition memory. Cave et al. found that arbitrary color changes between study and test had no effect on the hit rates for same- or different-colored targets after a 1 -h delay, but there was a very small but significant difference between hits for same-colored targets $(81.6 \%)$ and differentcolored targets $(78.5 \%)$ after a 48 -h delay. In the present research, an arbitrary color transformation between study and test may produce a small impairment in the recognition of previously shown possible or impossible objects. But, consistent with transformations of reflection or size, a color transformation should have no effect on affective preference for previously viewed objects because this surface feature change does not alter object form.

\section{Method}

The subjects, 48 Wesleyan University students who received introductory psychology credit and who had no prior experience, took part in a $2 \times 2 \times 2 \times 2$ mixed factorial design. Study-test color (same vs. different) and test order (recognition-affect vs. affect-recognition) were manipulated as between-subjects variables; object type (possible vs. impossible objects) and test type (recognition vs. affective preference) were manipulated as withinsubjects variables.

Except for a difference in color, all stimuli and viewing conditions were the same as those used in Experiment 1. The stimuli appeared as red or yellow objects on a dark surround when projected through colored photographic filters. Half of the subjects studied red objects and half studied yellow objects. Subjects taking the recognition test were told that the target objects might appear in the same color as study or in a different color. They were told to try to recognize the target object regardless of its color. The red and yellow stimuli were counterbalanced over study and test conditions, and any change in the color filter on the tachistoscope was done without the subjects' knowledge between study and test. All other stimulus and procedural details were identical to those in the prior experiments.

\section{Results and Discussion}

Study stimulus color and test order effects were absent for recognition and affect (all $F_{\mathrm{S}}<1$ ), permitting the data to be collapsed over color and test order conditions for pre- sentation in Table 3. Once again, performance was better for possible than for impossible objects for recognition $\left[F(1,44)=27.65, M S_{\mathrm{e}}=.018, p<.0001\right]$ and affect $\left[F(1,44)=14.35, M S_{\mathrm{e}}=.033, p<.0005\right]$, and, when the data were collapsed over the same-different color conditions (bottom row of Table 3), greater-than-chance recognition and affect were found for both object types by one-tailed $t$ tests (Bonferroni correction $=.05 / 2$ for each measure; $p s<.05$ ).

Most important, Table 3 indicates that there was no main effect of the color transformation on either recognition $\left[F(1,44)=1.24, M S_{\mathrm{e}}=.023, p>.05\right]$ or affect $(F<1)$. For recognition, there was a marginal interaction of studytest color (same vs. different) and object type $[F(1,44)=$ $3.06, M S_{\mathrm{e}}=.018, p<.09$ ], suggesting a subtle effect of the color transformation on impossible objects (Table 3 ). However, a replication experiment with 48 additional subjects using the colors red and green yielded no main effects or interactions involving study-test color and recognition or affect (all $p s>.05$ ), and the same results were obtained when the data were collapsed across experiments yielding a total of 96 subjects (all $F \mathrm{~s}<1$ ). Nor is the lack of a color transformation effect likely due to the presence of a ceiling effect for recognition. The same high level of recognition for unchanged objects was found in Experiment 2 (Table 2), and a size transformation effect was observed.

The absence of an effect of a color transformation on affective preference is consistent with prior research on picture priming (Cave et al., 1996) and implies that implicit memory for visual objects is insensitive to color transformations. Similarly, the lack of effect on recognition suggests that color is not critical for recognizing arbitrarily colored objects in a forced-choice recognition task after a minimal delay. It is important to remember that the subjects in the present experiment were shown 60 study trials in one color and 24 test trials in either that same color or a different color for all test trials (same or different object color for study and test was a betweensubjects variable). Therefore, it is difficult to imagine that the lack of an effect of color change on recognition was due to the subjects' being ignorant of object color, especially when they encoded the objects sufficiently to produce high recognition. Rather, postexperimental debriefing indicated that the subjects knew the color of the study and test objects, and they knew when the objects changed color between study and test. At least for the present conditions, a surface change in object color was ir-

Table 3

Mean Percentage of Target Objects Selected in Experiment 3: Color

\begin{tabular}{|c|c|c|c|c|c|c|c|c|c|c|c|c|}
\hline \multirow{4}{*}{$\begin{array}{c}\text { Study-Test } \\
\text { Color }\end{array}$} & \multicolumn{6}{|c|}{ Recognition Test } & \multicolumn{6}{|c|}{ Affect Test } \\
\hline & \multicolumn{4}{|c|}{ Object Type } & \multirow[b]{3}{*}{$M$} & \multirow[b]{3}{*}{$S E$} & \multicolumn{4}{|c|}{ Object Type } & \multirow[b]{3}{*}{$M$} & \multirow[b]{3}{*}{$S E$} \\
\hline & \multicolumn{2}{|c|}{ Possible } & \multicolumn{2}{|c|}{ Impossible } & & & \multicolumn{2}{|c|}{ Possible } & \multicolumn{2}{|c|}{ Impossible } & & \\
\hline & $M$ & $S E$ & $M$ & $S E$ & & & $M$ & $S E$ & $M$ & $S E$ & & \\
\hline Same & 92.4 & 3.0 & 82.6 & 3.2 & 87.5 & 2.3 & 73.2 & 5.2 & 60.4 & 4.5 & 66.8 & 3. \\
\hline Different & 93.7 & 3.1 & 74.3 & 3.3 & 84.0 & 2.7 & 75.7 & 4.6 & 60.4 & 4.8 & 68.1 & \\
\hline$M$ & 93.1 & 2.2 & 78.5 & 2.4 & & & 74.4 & 3.4 & 60.4 & 3.2 & & \\
\hline
\end{tabular}

Note-Chance performance is $50 \%$ for both tests. 
relevant for recognition (and affect) performance. To date, an effect of an arbitrary color transformation on object recognition has been observed only after a lengthy delay between study and test and, even then, the magnitude of the effect was very small (Cave et al., 1996).

\section{GENERAL DISCUSSION}

This research has shown that stimulus transformations of left-right orientation or size impaired recognition memory but not affective preference, whereas a transformation of stimulus color did not influence either measure. The dissociations involving reflection or size are consistent with the results from recognition and picture naming or object decision priming tasks (Biederman \& E. E. Cooper, 1991, 1992; L. A. Cooper et al., 1992) and indicate that the affective preference test is appropriately considered a measure of implicit memory. Whether objects are tested by picture name priming, object decision priming, or affective preference, they are not influenced by reflection or size transformations that do not alter stimulus form. Thus, surface transformations of reflection or size are two more variables to add to those (e.g., duration and number of stimulus exposures and delay between study and test) that dissociate recognition and affective preference in the mere exposure paradigm (see Seamon et al., 1983a, 1983b, 1984,1995 ). All of these variables influenced recognition, but had little or no effect on affective preference. As noted by Cave et al. (1996), explicit measures of memory appear to be specifically sensitive to the very qualities that implicit measures are not.

The present research also demonstrated that possible objects were recognized and liked better than impossible objects, and that greater than chance performance was observed for both object types on both measures of memory. These results confirm those of Seamon et al. (1995) using the same stimuli and procedures, and they indicate that implicit memory can be reliably demonstrated for possible and impossible objects in the mere exposure paradigm. Under different study and test conditions, Schacter et al. (e.g., 1990, 1991) have shown that object type dissociates recognition and object decision priming, as priming has been observed only for possible objects. However, a recent study by Carrasco and Seamon (1996) has demonstrated reliable priming for both stimulus types in the object decision priming task when the perceived complexity of the possible and impossible objects is equated. Those results, together with the present results, show that a failure to observe priming for impossible objects is not a general characteristic of implicit memory. As noted by Roediger and Srinivas (1993), variables need to be examined over a variety of implicit measures to determine whether specific results generalize across different tasks. Research has now shown that implicit memory can be reliably demonstrated for possible and impossible objects in the affective preference task (Seamon et al., 1995; the present experiments) and the object decision task (Carrasco \& Seamon, 1996).
One way to account for the present findings is to assume that dissociations of explicit and implicit memory reflect the output of different memory systems. This multiple memory systems approach is exemplified by the recognition and object decision priming research of Schacter, L. A. Cooper, and their colleagues (L. A. Cooper et al., 1992; Schacter et al., 1990, 1991). These researchers suggested that an episodic memory system is responsible for recognition, whereas a structural description system is responsible for object decision priming. According to L. A. Cooper et al. (1992), the episodic system is used to differentiate one object from another because it codes distinctive spatial, temporal, contextual, and semantic information about objects. This is why study-test changes in the spatial dimensions of left-right orientation or size impair object recognition. The structural description system, on the other hand, does not code these distinctive features. Its job is to analyze the structural relations among the components of a visual object to compute a part-based, three-dimensional representation called the "structural description." Object transformations involving reflection, size, or color do not alter these structural descriptions because representations from this system code only the invariants of perceptual structure (L. A. Cooper et al., 1992). Consequently, priming in the object decision task is not influenced by surface feature changes that preserve object form. Biederman and his colleagues (e.g., Biederman \& Ju, 1988; E. E. Cooper et al., 1992) have taken a similar position, arguing that the representations that support picture name priming are structural configurations of object parts (specifically, geometric primitives called "geons") that are insensitive to surface changes in orientation, size, location, or color.

If we apply this approach to the mere exposure paradigm, the present dissociations of recognition and affective preference would be attributed to the output of different memory systems. Recognition performance is sensitive to stimulus changes in reflection or size because it is based on episodic memory, a system that codes these distinctive stimulus features. Affective preference is insensitive to these transformations because, like object decision priming, it is based on the structural description system, and left-right orientation or size information is not coded in structural descriptions. Accordingly, subjects may "like" previously shown objects for essentially the same reason that they demonstrate object decision priming: Previously presented objects already have structural description representations available to facilitate the processing of those objects in the future.

This interpretation of the mere exposure effect was presented previously by Seamon et al. (1995), and it is consistent with an earlier interpretation of affective preference as reflecting liking based on perceptual fluency. For example, Seamon et al. (1983a) suggested that mere exposure to previously unfamiliar stimuli can lead to familiarity with processing those stimuli. Stimulus processing familiarity, expressed as perceptual fluency (Jacoby \& Dallas, 1981), can serve as the basis for affective pref- 
erence. Specifically, when subjects are presented with studied and nonstudied visual objects, they "like" the studied objects more than the nonstudied objects because of differences in perceptual fluency. (Bornstein, 1992, and Bornstein \& D'Agostino, 1992, have recently adopted a similar interpretation of the mere exposure effect.) Applied to the present results, this interpretation would hold that previously studied objects are more easily processed than are novel objects because prior stimulus exposures have produced structural description representations for those objects. The availability of a structural description for an object serves as the basis for perceptual fluency and, in a task requiring an affective decision, for affective preference as well. According to this view, it is the presence of structural description representations, rather than emotional responses, that determines affective preferences for visual stimuli in the mere exposure paradigm. Although the mere exposure effect remains open to different theoretical interpretations and additional work is needed before firm conclusions can be drawn (see Murphy, Monahan, \& Zajonc, 1995, and Zajonc, 1980, for a view that emphasizes emotional responses), the present results are consistent with earlier research on object perception and memory (e.g., Biederman \& E. E. Cooper, 1992; L. A. Cooper et al., 1992; Jolicoeur, 1987), suggesting that the perceptual fluency interpretation warrants serious consideration.

For perceptual transformations of reflection or size, few researchers disagree over the interpretation of the recognition impairments that these stimulus changes produce (Biederman \& E. E. Cooper, 1992; L. A. Cooper et al., 1992; Jolicoeur, 1987). The impairments strongly imply that the representations that support explicit recognition code distinctive spatial information. However, there remains considerable debate about the nature of the representations that support implicit memory measures. Structural description models assume part-based representations that do not code specific surface features. For L. A. Cooper et al. (1992), these representations are "abstract" for surface features such as left-right orientation and size; for Biederman and his colleagues, these representations lack specification regarding object orientation in depth, location, and color as well (e.g., Biederman \& Gerhardstein, 1993; E. E. Cooper et al., 1992). The finding by Biederman and Gerhardstein (1993) that rotating familiar objects in depth did not reduce priming in a picture naming task has generated the most controversy. This finding is consistent with a structural description model that assumes surface feature invariance, but it is at odds with object recognition models that assume viewpoint specificity. According to these models, representations that support priming and recognition are "viewer centered" regarding changes in orientation (see, e.g., Srinivas, 1993, 1995; Tarr, 1995). For example, Srinivas (1995) studied recognition and priming for familiar and novel three-dimensional objects that were presented in the same orientation as study or rotated in depth. Recognition was impaired by depth rotations, as was priming for many conditions, leading her to conclude that object representations in explicit and implicit memory are largely viewpoint specific for orientation. A similar conclusion was reached by Tarr in an object naming task. He observed priming for novel objects only when they were presented in orientations that had been viewed earlier.

As a result of this controversy, there is disagreement about whether implicit memory representations are sensitive to changes in stimulus orientation. The fact that a 2-dimensional, left-right orientation change has consistently shown no effect on a variety of implicit memory measures may demonstrate an exception to the more general three-dimensional orientation effects. As Corballis (1988) has noted, we rarely discriminate reflected images in the natural world, and it would be advantageous to respond to both in the same fashion. At present, the disagreement over whether different representations are necessary to describe explicit and implicit memory (i.e., a viewpoint-specific representation for one; a part-based structural description for the other) or if the same viewpoint-specific representations can support both must await additional research. Extending the suggestion made earlier by Roediger and Srinivas (1993), we need to examine the effect of a depth-orientation transformation on a variety of implicit memory measures to observe whether sensitivity or insensitivity to this transformation is the more general characteristic. Given the present results, the affective preference test may be an ideal candidate for this task because it can be used with novel objects.

\section{REFERENCES}

Biederman, I., \& COOPER, E. E. (1991). Evidence for complete translational and reflectional invariance in visual object priming. Perception, 20, 585-593.

Biederman, I., \& Cooper, E. E. (1992). Size invariance in visual object priming. Journal of Experimental Psychology: Human Perception \& Performance, 18, 121-133.

Biederman, I., \& Gerhardstein, P. C. (1993). Recognizing depthrotated objects: Evidence for 3D viewpoint invariance. Journal of Experimental Psychology: Human Perception \& Performance, 19, $1162-1182$.

Biederman, I., \& Ju, G. (1988). Surface versus edge-based determinants of visual recognition. Cognitive Psychology, 20, 38-64.

Bonanno, G. A., \& Stillings, N. A. (1986). Preference, familiarity, and recognition after repeated brief exposures to random geometric shapes. American Journal of Psychology, 99, 403-415.

BorNSTEIN, R. F. (1992), Subliminal mere exposure effects. In R. F. Bornstein \& T. S. Pittman (Eds.), Perception without awareness Cognitive, clinical and social perspectives (pp. 191-210). New York: Guilford.

Bornstein, R. F., \& D'Agostino, P. R. (1992). Stimulus recognition and the mere exposure effect. Journal of Personality \& Social Psychology, 63, 545-552.

Bornstein, R. F., LeONe, D. R., \& Galley, D. J. (1987). The generalizability of subliminal mere exposure effects: Influence of stimuli perceived without awareness on social behavior. Journal of Personality \& Social Psychology, 53, 1070-1079.

Carrasco, M., \& Seamon, J. G. (1996). Priming impossible figures in the object decision test: The critical importance of perceived stimulus complexity. Psychonomic Bulletin \& Review, 3, 344-351.

CAve, C. B., Bost, P. R., \& CoBB, R. E. ( 1996). Effects of color and pattern on implicit and explicit picture memory. Journal of Experimental Psychology: Learning, Memory, \& Cognition, 22, 639-653 
CAve, C. B., \& Squire, L. R. (1992), Intact and long lasting priming in amnesia. Journal of Experimental Psychology: Learning, Memory, \& Cognition, 18, 509-520.

Cooper, L. A., Schacter, D. L., Ballesteros, S., \& Moore, C. (1992). Priming and recognition of transformed three-dimensional objects: Effects of size and reflection. Journal of Experimental Psychology: Learning, Memory, \& Cognition, 18, 43-57.

Corballis, M. C. (1988). Recognition of disoriented shapes. Psychological Review, 95, 115-123.

GRAF, P. (1994). Explicit and implicit memory: A decade of research. In C. Umiltà \& M. Moscovitch (Eds.), Attention and performance $X V$ : Conscious and nonconscious information processing (pp. 681 696). Cambridge, MA: MIT Press.

JACOBY, L. L., \& DALLAS, M. (1981). On the relationship between autobiographical memory and perceptual learning. Journal of Experimental Psychology: General, 110, 306-340.

JACOBY, L. L., Toth, J. P., \& YONELINAS, A. P. (1993). Separating conscious and unconscious influences of memory: Measuring recollection. Journal of Experimental Psychology: General, 122, 139-154.

JOLICOEUR, P. (1987). A size-congruency effect in memory for visual shape. Memory \& Cognition, 15, 531-543.

Kolers, P. A., Duchnicky, R. L., \& Sundstroem, G. (1985). Size in visual processing of faces and words. Journal of Experimental Psychology: Human Perception \& Performance, 11, 726-751.

Kunst-Wilson, W. R., \& ZaJONC, R. B. (1980). Affective discrimination of stimuli that cannot be recognized. Science, 207, 557-558.

Mandler, G., NaKamura, Y., \& Van ZandT, B. J. (1987). Nonspecific effects of exposure to stimuli that cannot be recognized. Journal of Experimental Psychology: Learning, Memory, \& Cognition, 13, 646-648.

Milliken, B., \& Jolicoeur, P. (1992). Size effects in visual recognition memory are determined by perceived size. Memory \& Cognition, 20, 83-95.

Moscovitch, M., Goshen-Gottstein, Y., \& Vriezen, E. (1994). Memory without conscious recollection: A tutorial review from a neuropsychological perspective. In C. Umiltà \& $\mathrm{M}$. Moscovitch (Eds.), Attention and performance XV: Conscious and nonconscious information processing (pp. 619-660). Cambridge, MA: MIT Press.

Murphy, S. T., Monahan, J. L., \& Zajonc, R. B. (1995). Additivity of nonconscious priming: Combined effects of priming and exposure. Journal of Personality \& Social Psychology, 69, 589-602.

OstergaARD, A. L., \& DavidofF, J. B. (1985). Some effects of color on naming and recognition of objects. Journal of Experimental Psychology: Learning, Memory, \& Cognition, 11, 579-587.

Price, C, J., \& Humphreys, G. W. (1989). The effects of surface detail on object categorization and naming. Quarterly Journal of Experimental Psychology, 41 A, 797-827.

RichaRdSON-KLAVEHN, A., \& BJoRK, R. A. (1988). Measures of memory. Annual Review of Psychology, 39, 475-543.

RoEDIGER, H. L., III, \& BLAXTON, T. A. (1987). Effects of varying modality, surface features, and retention interval on priming in word-fragment completion. Memory \& Cognition, 15, 379-388.

RoEdiger, H. L., III, \& MCDERMOTt, K. B. (1993). Implicit memory in normal subjects. In F. Boller \& J. Grafman (Eds.), Handbook of neuropsychology (Vol. 8, pp. 63-131). Amsterdam: Elsevier.

RoEDIGER, H. L., III, \& SRINIVAS, K. (1993). Specificity of operations in perceptual priming. In P. Graf \& M. E. J. Masson (Eds.), Implicir memory: New directions in cognition, development, and neuropsychology (pp. 17-48). Hillsdale, NJ: Eribaum.

SCHACTER, D. L. (1987). Implicit memory: History and current status. Journal of Experimental Psychology: Learning, Memory, \& Cognition, 13, 501-518.

SCHACTER, D. L., BOWERS, J., \& BOOKER, J. (1989). Intentional awareness and implicit memory: The retrieval intentionality criterion. In S. Lewandowsky, J. Dunn, \& K. Kirsner (Eds.), Implicit memory: Theoretical issues (pp. 47-65). Hillsdale, NJ: Erlbaum.

SCHACTER, D. L., \& CHURCH, B. A. (1992). Auditory priming: Implicit and explicit memory for words and voices. Journal of Experimental Psychology: Learning, Memory, \& Cognition, 18, 915-930.

SChacter, D. L., CoOper, L. A., \& Delaney, S. M. (1990). Implicit memory for unfamiliar objects depends on access to structural descriptions. Journal of Experimental Psychology: General, 119, 5-24.

Schacter, D. L., Cooper, L. A., Delaney, S. M., Peterson, M. A., \& Tharan, M. (1991). Implicit memory for possible and impossible objects: Constraints on the construction of structural descriptions. Journal of Experimental Psychology: Learning, Memory, \& Cognition, 17, 3-19.

Schacter, D. L., CoOper, L. A., \& Treadwell, J. (1993). Preserved priming of novel objects across size transformations in amnesic patients. Psychological Science, 4, 331-335.

Seamon, J. G., Brody, N., \& KaUfF, D. M. (1983a). Affective discrimination of stimuli that are not recognized: Effects of shadowing, masking, and cerebral laterality. Journal of Experimental Psychology: Learning, Memory, \& Cognition, 9, 544-555.

Seamon, J. G., Brody, N., \& Kauff, D. M. (1983b). Affective discrimination of stimuli that are not recognized: II. Effect of delay between study and test. Bulletin of the Psychonomic Society, 21, 187-189.

Seamon, J. G., Ganor-Stern, D., Crowley, M. J., Wilson, S. M., Weber, W. J., O'Rourke, C. M., \& Mahoney, J. K. (1994, November). Mere exposure for transformed three-dimensional abjects Poster presented at the annual meeting of the Psychonomic Society, St. Louis.

Seamon, J. G., Marsh, R. L., \& Brody, N. (1984). Critical importance of exposure duration for affective discrimination of stimuli that are not recognized. Journal of Experimental Psychology: Learning, Memory, \& Cognition, 10, 465-469.

Seamon, J. G., Williams, P. C., Crowley, M. J., Kim, I. J., Langer, S. A., ORNe, P. J., \& WISHENGRAD, D. L. (1995). The mere exposure effect is based on implicit memory: Effects of stimulus type, encoding conditions, and number of exposures on recognition and affect judgments. Journal of Experimental Psychology: Learning, Memory, \& Cognition, 21, 711-721.

SNODGRass, J. G., \& VANDERWart, M. (1980). A standardized set of 260 pictures: Norms for name agreement, image agreement, familiarity, and visual complexity. Journal of Experimental Psychology. Learning, Memory, \& Cognition, 6, 174-215.

SQuire, L. R. (1992). Memory and the hippocampus: A synthesis from findings with rats, monkeys, and humans. Psychological Review, 99, 195-231

SRINIVAS, K. (1993). Perceptual specificity in nonverbal priming. Journal of Experimental Psychology: Learning, Memory, \& Cognition, 19, 582-602.

SRINIVAS, K. (1995). The representation of rotated objects in explicit and implicit memory. Journal of Experimental Psychology: Learning, Memory, \& Cognition, 21, 1019-1036.

TARR, M. J. (1995). Rotating objects to recognize them: A case study of the role of viewpoint dependency in the recognition of threedimensional objects. Psychonomic Bulletin \& Review, 2, 55-82.

WELDON, M.S. (1991). Mechanisms underlying priming on perceptual tests. Journal of Experimental Psychology: Learning, Memory, \& Cognition, 17, 526-541.

Wurm, L. H., Legge, G. E., Isenberg, L. M., \& Luebker, A. (1993) Color improves object recognition in normal and low vision. Jour nal of Experimental Psychology: Human Perception \& Performance, 19, 899-911

ZAJONC, R. B. (1968). Attitudinal effects of mere exposure. Journal of Personality \& Social Psychology Monograph Supplements, 9(2, Pt. 2), 1-27.

Zajonc, R. B. (1980). Feeling and thinking: Preferences need no in ferences. American Psychologist, 35, 151-175.

(Manuscript received December 13, 1995; revision accepted for publication April 24, 1996.) 